\title{
Adsorbent filled membranes for gas separation. Part 1. Improvement of the gas separation properties of polymeric membranes by incorporation of microporous adsorbents*
}

\author{
J.-M. Duval ${ }^{a, * *}$, B. Folkers ${ }^{a}$, M.H.V. Mulder ${ }^{a}$, G. Desgrandchamps ${ }^{b}$ and C.A. Smolders ${ }^{a}$ \\ 'University of Twente, Department of Chemical Technology, $P O$ Box 217, 7500 AE Enschede (The Netherlands) \\ 'Elf Aquitaine, Groupement de Recherches de Lacq, PO Box 34 Lacq, 64170 Artix (France)
}

(Received May 18, 1992, accepted in revised form August 2, 1992)

\begin{abstract}
The effect of the introduction of specific adsorbents on the gas separation properties of polymeric membranes has been studied For this purpose both carbon molecular sieves and zeolites are considered The results show that zeolites such as slicate-1, 13X and KY improve to a large extent the separation properties of poorly selective rubbery polymers towards a mixture of carbon dioxide/methane Some of the filled rubbery polymers achieve intrinsic separation properties comparable to cellulose acetate, polysulfone or polyethersulfone However, zeolite $5 \mathrm{~A}$ leads to a decrease in permeability and an unchanged selectivity. This is due to the impermeable character of these particles, $1 \mathrm{e}$ carbon dioxide molecules cannot diffuse through the porous structure under the conditions applied Using slicate-1 also results in an improvement of the oxygen/nitrogen separation properties which is mainly due to a kinetic effect Carbon molecular sieves do not improve the separation performances or only to a very small extent This is caused by a mainly dead-end (not interconnected) porous structure which is inherent to their manufacturing process
\end{abstract}

Keywords gas separation; zeolite filled membrane; carbon molecular sieves, composite membranes

\section{Introduction}

Adsorbents such as zeolites and molecular sieving carbons are well known for the separation of gaseous mixtures by pressure-swing ad-

*Paper presented at the Int Conf on 'Engmeering of Membrane Processes', Garmisch-Partenkırchen, Germany, May 13-15, 1992

*To whom correspondence should be addressed sorption. This process involves the use of the specific microporous adsorbents in a semi-continuous way with sorption-desorption cycles. In the present study, the adsorbents have been incorporated into a polymeric matrix to form a heterogeneous membrane. In filled membranes the selective properties of the specific adsorbents are used in a continuous way.

Such a concept has already been shown to 
improve the separation properties of polymers for pervaporation [1,2] and gas separation [3]. In the case of pervaporation of ethanol/water mixtures using silicone rubber membranes, both the ethanol selectivity and the permeability were enhanced by the incorporation of silicalite-1 particles into the polymer matrix [1]. The same type of membranes showed improved gas separation properties [2]. However these studies were limited to one type of zeolite or one polymeric phase. The present paper aims at giving a larger overview of the influence of various zeolites and molecular sieve carbons on the gas separation properties of polymer materials. Therefore four zeolites with different hydrophilic/hydrophobic properties and various pore sizes were incorporated into five different polymers.

\section{Basic properties of zeolites and carbon molecular gieves}

\section{Zeolites}

It is beyond the scope of this paper to give an extended and detailed description of the microporous adsorbents considered (see review articles [4-7]). However some basic characteristics which are of importance for the present study will be summarized briefly. Zeolites are crystalline alumino-silicates composed of $\mathrm{AlO}_{4}$ and $\mathrm{SiO}_{4}$ tetrahedra, which build up a network of channels and cavities. The microcrystalline voids and channels which are interconnected are responsible for the very specific properties of these adsorbents. The aperture size is typically in the range of molecular dimensions, i.e. 3 to $10 \AA$. Because the aluminium atom is trivalent, an excess of negative charge is introduced in the network when $\mathrm{Si}$ is replaced by $\mathrm{Al}$ in the tetrahedra. This charge is compensated by non-framework cations, located near the negative charges; the most common ones are $\mathrm{Na}^{+}, \mathrm{K}^{+}, \mathrm{Ca}^{2+}$. The number of cations is thus determined by the number of aluminium atoms in the framework. Because of the presence of cations, these zeolites are polar adsorbents. This means that molecules such as water, ammonia (strong dipoles), carbon dioxide, nitrogen (quadrupolar) and aromatic hydrocarbons ( $\pi$ layer interaction) are adsorbed more strongly than non polar species of comparable molecular weight. Zeolites with a high $\mathrm{Si} / \mathrm{Al}$ ratio are hydrophobic and the adsorption is mainly governed by Van der Waals forces.

Therefore four main factors influence the properties of a zeolite:

- pore size which acts on the ability of a molecule to enter and diffuse through the zeolite framework.

- $\mathrm{Si} / \mathrm{Al}$ ratio which determines the number of cations and thus the hydrophilicity of the zeolite framework.

- type of cation (valence and size)

- direction of the pores $(1,2$ or $3 D$ porous network).

Some applications of zeolites in the separation of gaseous mixtures are the dehydration of industrial gases using hydrophilic zeolites, the separation of air by preferential equilibrium sorption of nitrogen or the removal of $\mathrm{H}_{2} \mathrm{~S}$ from sour gas [4].

\section{Carbon molecular sieves}

Carbon molecular sieves are characterized by a pore size distribution, which is much narrower than in the case of common active carbons $[7,8]$. It means that, contrary to zeolites, carbon molecular sieves cannot be given a definite pore size but only a mean pore size which is in the range of molecular dimensions. Furthermore, their internal surface is basically hydrophobic, with possible variations due to acidic surface groups [9]. Carbon molecular sieves are industrially used to separate air by adsorption of oxygen and also to remove carbon dioxide from landfill gas [10]. 


\section{Experimental}

\section{Adsorbents}

The adsorbents considered are the zeolites $5 \mathrm{~A}$ (Ceca S.A., France, crystal density $\rho_{c}=1.48 \mathrm{~g}$ / $\mathrm{cm}^{3}$ ), Silicalite-1 (Union Carbide, USA, $\rho_{\mathrm{c}}=1.76 \mathrm{~g} / \mathrm{cm}^{3}$ ), KY (Ceca S.A., $\rho_{\mathrm{c}}=1.52 \mathrm{~g} /$ $\mathrm{cm}^{3}$ ), 13X (Ceca S.A., $\rho_{\mathrm{c}}=1.54 \mathrm{~g} / \mathrm{cm}^{3}$ ) and the carbon molecular sieves Cecalite (Ceca S.A), Carbosieve (Supelco Separation Technologies, USA) and W20 (Norit N.V., The Netherlands). Furthermore, non porous silica (Sigma) was used as inert filler ( $\mathrm{N}_{2}$ BET surface area: $5.8 \mathrm{~m}^{2} / \mathrm{g}$ ). The zeolites were activated in air at $350^{\circ} \mathrm{C}$ for two hours except for silicalite where an activation temperature of $500^{\circ} \mathrm{C}$ was applied (calcination of the template used during synthesis). The crystallinity of the zeolites was examined by $\mathrm{X}$-ray powder diffraction. The size of the zeolite particles was typically in the range 1-5 $\mu \mathrm{m}$.

The carbons were activated in a vacuum oven at $150^{\circ} \mathrm{C}$ for $24 \mathrm{hr}$. The adsorbents were then kept in a vacuum oven at room temperature. Table 1 (and Table A-1 in the Appendix) gives some basic properties of these microporous adsorbents.

\section{Polymers}

Polydimethylsiloxane (PDMS, RTV 615A and B, General Electric), ethylene-propylene rubber (EPDM, Keltan 578, DSM), polychloroprene (PCP, Aldrich), and nitrile butadiene rubbers (Polysar) with two different amounts of acrylonitrile segments: $\mathbf{4 5 \%}$, Krynac $\mathbf{4 5 . 5 0}$ (NBR 45) and 50\%, Krynac 50.75 (NBR 50) were used as polymers.

\section{Membrane preparation}

Membranes were prepared by dispersion of the adsorbent phase in the polymeric solution, followed by a casting-evaporation process. Hexane and chloroform were used as solvents. The evaporation step was carried out first overnight under a nitrogen stream, then in a vacuum oven at $30^{\circ} \mathrm{C}$ for at least $24 \mathrm{hr}$. The membranes thus obtained were 50 to $200 \mu \mathrm{m}$ thick. The homogenous dispersion of the particles was observed by scanning electron microscopy (Fig. $1)$.

\section{Equipment and methods}

The gas separation properties were determined by means of an automized setup with a mixture of carbon dioxide and methane (25/75 vol.\%), pure oxygen and pure nitrogen at room temperature $\left(24^{\circ} \mathrm{C}\right)$. The low pressure side was kept under vacuum $\left(10^{-2}-10^{-1}\right.$ mbar) while the feed pressure was set at 5.3 bars. The permeate flux was determined by measuring a pressure increase in a calibrated volume, the permeate pressure remaining negligible com-

TABLE 1

Main characteristıcs of the zeolitic adsorbents Kınetic diameters of the gas molecules used are: $\mathrm{CO}_{2} 33 \AA$, $\mathrm{CH}_{4} 3.8 \AA \mathrm{A}_{2}$ $346 \AA, N_{2} 364 \AA$

\begin{tabular}{llclll}
\hline & Pore size $(\AA)$ & Si $/ \mathrm{Al}$ & Cation & Directions & Pore vol $\left(\mathrm{cm}^{3} / \mathrm{g}\right)$ \\
\hline $5 \mathrm{~A}$ & 45 & 1 & $\mathrm{Na}^{+} / \mathrm{Ca}^{2+}$ & 3D & 0.28 \\
silicalite-1 & $53-56<->51-5.5$ & $\infty$ & - & 2D & 019 \\
KY & 7.4 & 26 & $\mathrm{~K}^{+}$ & $3 \mathrm{D}$ & - \\
$13 \mathrm{X}$ & 7.4 & 12 & $\mathrm{Na}^{+}$ & 3D & 036 \\
\hline
\end{tabular}




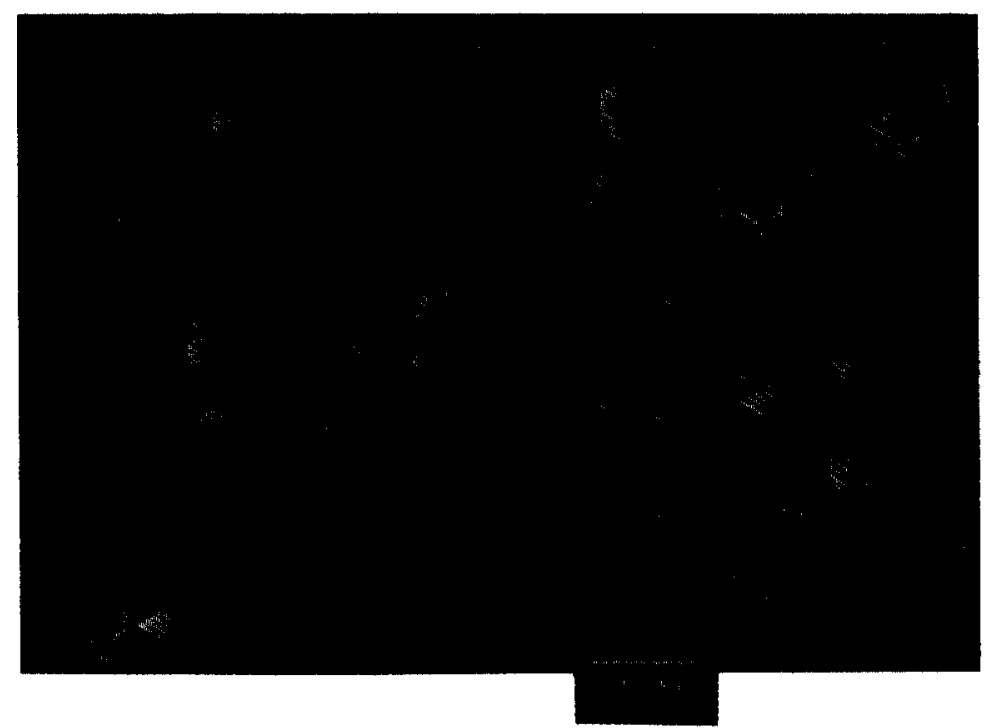

Fig 1 Cross section of a PDMS membrane filled with 60 wt \% of zeolte 5A

pared to the feed pressure. The permeabilities are expressed in barrer with 1 barrer $=10^{-10}$

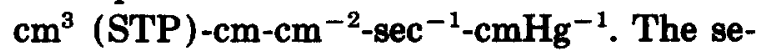
lectivity was calculated from the gas chromatographic analyses of the feed mixture and of the permeate in the case of $\mathrm{CO}_{2} / \mathrm{CH}_{4}$, and from the ratio of the pure gas permeabilities in the case of $\mathrm{O}_{2} / \mathrm{N}_{2}$. For more details about the experimental setup, see Ref. [11]. The permeation experiments were carried out until steady state was reached, which means from 1 to 5 days depending on the zeolite considered. The gas sorption experiments were carried out with a pressure-decay setup, as described elsewhere $[12,13]$. The membrane samples were evacuated at $30^{\circ} \mathrm{C}$ and $10^{-3}$ mbar for at least $15 \mathrm{hr}$ before measurement, in addition to the normal treatment. The experiments were carried out at $30^{\circ} \mathrm{C}$.

\section{Results and discussion}

The results obtained with carbon molecular sieves are given in the Appendix.
Gas permeation using zeolite filled membranes

\section{Carbon dioxide/methane}

The open porous structure of the zeolites results in an increase both in selectivity and permeability for carbon dioxide over methane in the case of silicalite- $1, K Y$ and $13 X$, as can be seen from Figs. 2 (a) and (b). Here EPDM was used as polymeric phase. The improvement of the separation properties increases when the volume fraction of zeolite in the polymer matrix increases, until the amount of adsorbent in the membrane surpasses an optimum. This results in the formation of nonselective voids as can be seen from the large increase in permeability and decrease in selectivity. It occurs when the volume fraction of zeolite is in the range of 45 to 55 percent (Fig. 2).

The largest improvement in selectivity and permeability for carbon dioxide was obtained using zeolite KY (Fig. 2), for which the pore size is about twice the kinetic diameter of carbon dioxide and methane (which are 3.3 and $3.8 \AA$ respectively ). Zeolite $13 \mathrm{X}$, which has basically the same pore size but a lower $\mathrm{Si} / \mathrm{Al}$ ratio, 

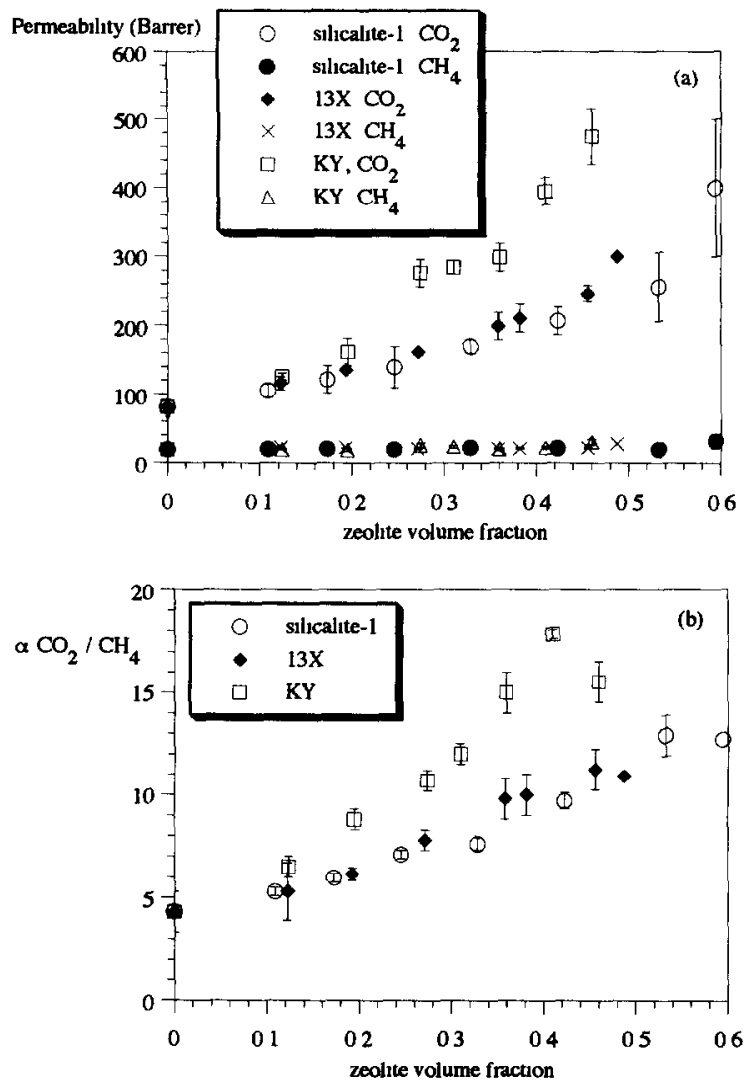

Fig 2 Effect of filling for the zeolites silicalite-1, 13X and KY on the $\mathrm{CO}_{2} / \mathrm{CH}_{4}$ separation properties of EPDM (a) = permeabilities, (b) selectivity. 1 barrer $=10^{-10} \mathrm{~cm}^{3}$

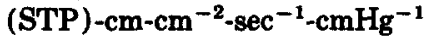

gave results comparable to silicalite- 1 whose pore size is $5.5 \AA$.

Contrary to the first three zeolites considered, zeolite $5 \mathrm{~A}$ does not enhance the membrane performance (Table 2), despite the fact that the pore size $(4.5 \AA)$ is large enough to fit the kinetic diameters of the gas molecules. The properties are similar to those of non-porous silica with respect to the effect on the gas permeation properties (Table 2). It means that the porous structure of zeolite $\mathbf{5 A}$ is not open for the permeation of gas molecules in the particular conditions encountered in the polymer matrix. Possible reasons for this phenomenon will be given later.
TABLE 2

Effect of zeolite 5A and non-porous sllica on PDMS and EPDM separation properties

\begin{tabular}{lll}
\hline & $P_{\mathrm{CO}_{2}}$ (barrer) & $\alpha_{\mathrm{CO}_{2} / \mathrm{CH}_{4}}$ \\
\hline PDMS & 2920 & 27 \\
PDMS +50 wt \% 5A & 1800 & 28 \\
PDMS + 28 wt.\% silica & 2407 & 28 \\
PDMS + 59 wt \% silıca & 1910 & 30 \\
& & \\
EPDM & 81 & 43 \\
EPDM + 52 wt \% 5A & 65 & 44 \\
EPDM +62 wt \% 5A & 50 & 45 \\
EPDM + 40 wt \% sllica & 72 & 45 \\
EPDM +53 wt \% sllica & 55 & 46 \\
\hline
\end{tabular}

From the results obtained it can be concluded that molecular sieving by size exclusion is not the only mechanism involved and that the affinity of the gas molecules for the zeolite internal surface plays also a major role.

Screening the results of a series of polymers shows that the zeolites silicalite- 1 and $\mathrm{KY}$ are able to increase significantly their separation properties. Especially in the case of a polymer the selectivity of which is about 15 for carbon dioxide/methane the results of the filled membranes are comparable to industrially used polymer membrane materials (cellulose acetate, polysulfone) as can be seen in Figs. 3(a) and (b) and Fig. 4. In these figures the diagonal lines show the results if the zeolites had no effect on the separation properties of the different polymers. All polymers showed improved selectivity and permeability for carbon dioxide when filled with silicalite-1 or $\mathrm{KY}$, despite the fact that for the polymers studied the permeabilities ranged from about 3 (NBR 50) to 3000 barrers (PDMS) and their selectivities from 2.7 (PDMS) to 17.5 (NBR 50). For example, the addition of 50 vol.\% of silicalite- 1 to NBR 50 gives a material with a selectivity of 29 and a permeability of 7 barrers. NBR 45 filled with 46 vol.\% of zeolite KY results in a material with 

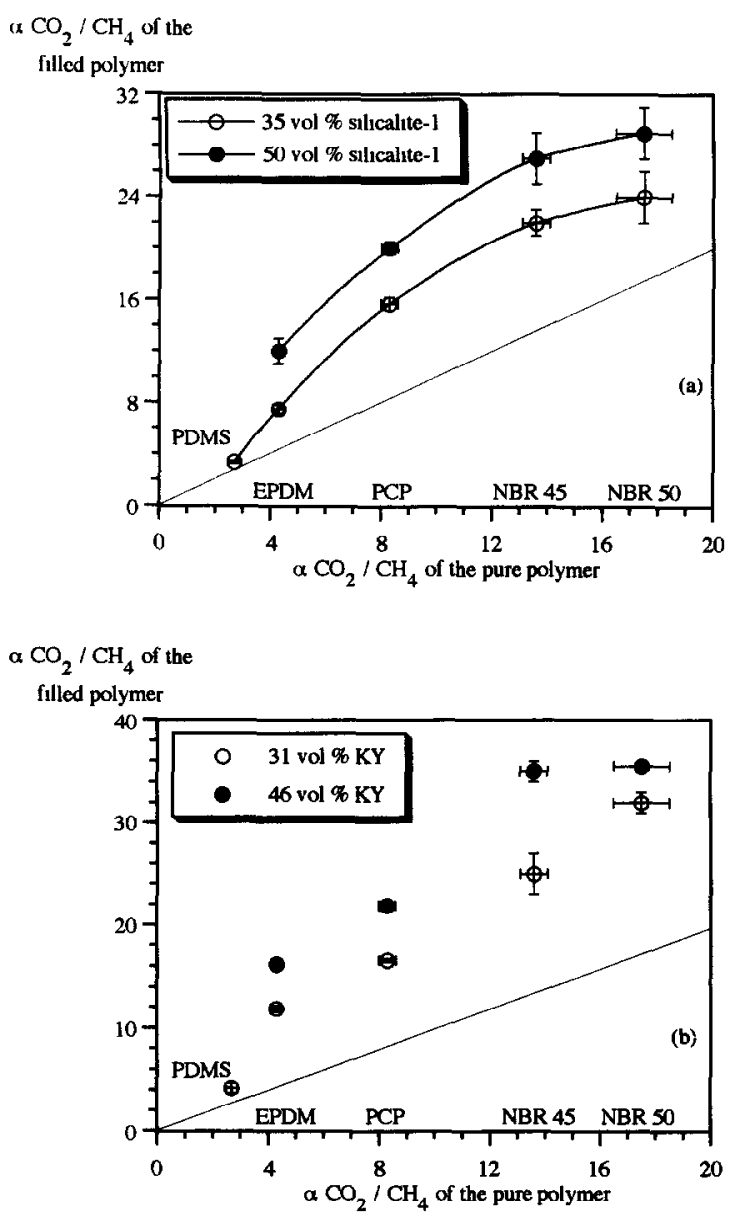

Fig. 3. Effect of the zeolites slicalite-1 (a) and KY (b) on the $\mathrm{CO}_{2} / \mathrm{CH}_{4}$ selectivity of various rubbery polymers

a selectivity of 35 and a permeability of 14 barrers for carbon dioxide.

Figures 3 and 4 also show that filling with zeolite $\mathrm{KY}$ always results in a larger improvement of the $\mathrm{CO}_{2}$ selectivity and permeability compared to silicalite-1 for a given volume fraction in a given polymer. This is in agreement with the observations for the single polymer EPDM when using different volume fractions. Silicalite-1 and type Y zeolite both show a sorption selectivity towards $\mathrm{CO}_{2}[7,14]$, but the selectivity obtained with $\mathrm{Y}$ ( $\mathrm{NaY}$ in Ref. [14]) is much larger, due to its hydrophilic surface. It may be assumed that the same is ob-

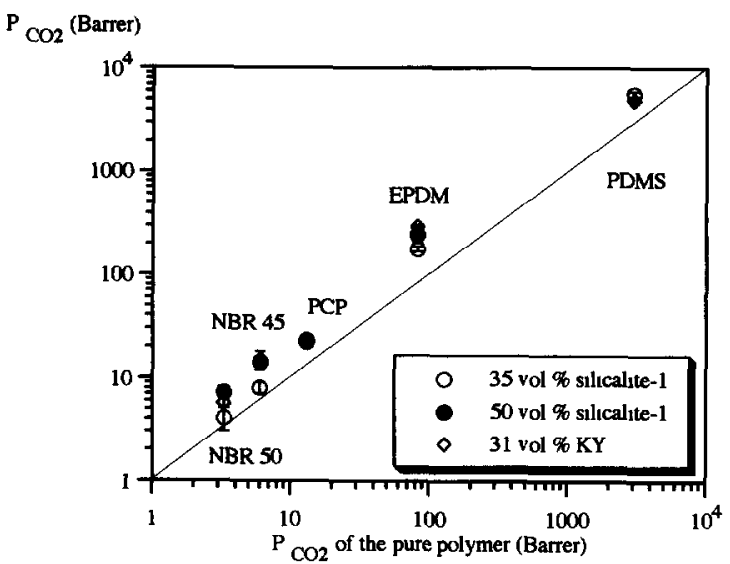

Fig 4 Effect of the zeolites silicalite-1 and $\mathrm{KY}$ on the $\mathrm{CO}_{2}$ permeabulity of various rubbery polymers $1 \mathrm{Barrer}=10^{-10}$ $\mathrm{cm}^{3}$ (STP) $-\mathrm{cm}-\mathrm{cm}^{-2}-\mathrm{sec}^{-1} \mathrm{cmHg}^{-1}$

served when the sodium cations are exchanged for potassium, which would explain the beneficial influence of $K Y$ on the permeation properties.

This concept may also be applied to improve the separation performance of very selective (glassy) polymers. This was also investigated but the results obtained were not that positive due to a very poor adhesion of the polymer matrix to the external surface of the zeolite, resulting in large voids between the polymer and the zeolite crystals. The incorporation of zeolites in glassy polymers is described elsewhere [15] and will not be considered here.

\section{Oxygen/nitrogen}

A very surprising effect was observed in the oxygen/nitrogen separation. Incorporation of silicalite- 1 resulted in an increase in the ideal selectivity for oxygen in the case of poorly selective rubbery polymers (Table 3 ). This was already observed for PDMS and our results are similar to those found in literature [2]. The selectivity values obtained with EPDM as polymeric phase are comparable to the intrinsic values of polymethylpentene or polydimethylphenylene oxide which are industrially used 
TABLE 3

Effect of silicalite-1 on $\mathrm{O}_{2} / \mathrm{N}_{2}$ separation properties of PDMS and EPDM

\begin{tabular}{lccc}
\hline & $P_{\mathrm{O}_{2}}$ (barrer) & $P_{\mathrm{N}_{2}}$ (barrer) & $\alpha_{\mathrm{O}_{2} / \mathrm{N}_{2}}$ \\
\hline PDMS & 606 & 289 & 21 \\
PDMS+28 vol \% slicalite-1 & 892 & 355 & 25 \\
PDMS+37 vol \% slicalite-1 & 998 & 373 & 27 \\
PDMS+47 vol \% slicalite-1 & 1370 & 521 & 26 \\
EPDM & 16 & 53 & 3 \\
EPDM +32 vol \% slicalite-1 & 29 & 75 & 39 \\
EPDM+53 vol \% slicalite-1 & 40 & 85 & 47 \\
\hline
\end{tabular}

membrane materials for air separation.

Silicalite shows a sorption selectivity for carbon dioxide over methane (separation factor: 2.7 at $25^{\circ} \mathrm{C}[8,14]$ ) but no significant equilibrium sorption selectivity for oxygen over nitrogen is reported for this zeolite [16]. The improvement in selectivity obtained for the filled membranes is mainly determined by a kinetic effect, i.e. the oxygen molecules can diffuse through the porous structure of silicalite-1 faster than the nitrogen molecules. This is comparable to what is observed with carbon molecular sieves which have almost no equilibrium sorption selectivity for oxygen but are used in pressure swing adsorption. Here the separation of air is based on a faster sorption rate of oxygen over nitrogen [17]. Such a kinetic selectivity towards oxygen is also observed with zeolite $4 A$ (pore size: $3.8 \AA$ ), which is even sorption selective towards nitrogen at equilibrium [18]. It should be noticed that silicalite-1 also enhances the nitrogen permeability with the polymers investigated, but this was not observed for methane.

\section{Gas sorption isotherms}

Carbon dioxide sorption isotherms show that the presence of zeolite particles in the membrane matrix enhances the carbon dioxide sorption capacity drastically (see Fig. 5). How-

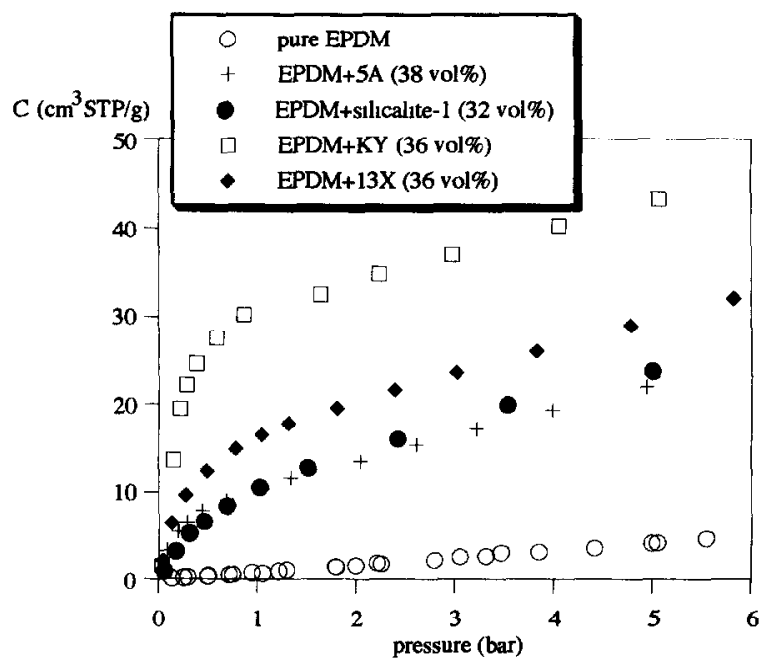

Fig 5 Carbon dioxide sorption isotherms of pure and zeolite filled EPDM, $T=30^{\circ} \mathrm{C}$

ever, when considering transport properties the sorbent should not only sorb the gas molecules but also allow these to diffuse under the driving force applied. This is indeed what is observed for silicalite-1, KY and 13X. On the other hand zeolite $5 \mathrm{~A}$ also enhances the sorption capacity of EPDM, but not the gas permeation properties (Table 2). This means that the sorbed gas molecules cannot diffuse through the zeolite porous structure but are trapped into the matrix and exhibit a very low mobility. There may be two reasons for this behaviour. The first one is that under permeation conditions, the gas 
molecules are very strongly bound to the sorption sites and cannot desorb (the heat of sorption of carbon dioxide in type A zeolite is greater than in type $\mathrm{Y}$ or in silicalite-1 [14] ); therefore they block the way for other molecules. The second reason is that water of hydration remains in the zeolite structure and cannot be removed by vacuum activation at room temperature (a high temperature would degrade the polymeric phase). The latter explanation is more likely to be correct because $5 \mathrm{~A}$ is a very hydrophilic zeolite with a high affinity for water resulting in a lower $\mathrm{CO}_{2}$ sorption capacity than expected from pure zeolite sorption data [19]. Moreover, Paul and Kemp [19] showed that activation of a $5 \mathrm{~A}$ filled silicone rubber membrane at $200^{\circ} \mathrm{C}$ prior to use does not make zeolite $\mathbf{5 A}$ beneficial for gas permeation, i.e. the permeability of the membrane is lowered and the diffusion time-lag drastically enhanced. Therefore even in-situ activation does not make much difference with respect to the permeation results.

In addition, it can be seen from the sorption isotherms that the zeolite resulting in the largest improvement of carbon dioxide sorption capacity (KY) also leads to the largest improvement of the carbon dioxide permeability and selectivity. Zeolite $13 \mathrm{X}$ gives a surprisingly low increase of the sorption capacity when considering its microporous volume and low $\mathrm{Si} / \mathrm{Al}$ ratio. These two factors should favor the sorption of carbon dioxide to a much larger extent than in the case of the hydrophobic silicalite-1 ( $\mathrm{Si}$ ) $\mathrm{Al}=\infty$ ). Here again, the presence of hydration water might play a decisive role. After the thermal activation and storage in the vacuum oven, it may be assumed that essentially all the water has been removed from the crystal structure. However, the preparation of the membrane and the gas separation experiments themselves involve water traces which will adsorb into the zeolite structure more preferentially than carbon dioxide. This effect can decrease the sorp- tion capacity to a substantial extent (like in the case of $5 \mathrm{~A}$ ) which then reduces the ability to improve the gas permeation properties. Nevertheless some improvement was observed with respect to $\mathrm{CO}_{2} / \mathrm{CH}_{4}$ permeation which can be attributed to the large pores present in $13 \mathrm{X}$ which are able to accomodate both carbon dioxide and water traces without blocking the diffusion path completely.

\section{Conclusions}

The carbon dioxide/methane separation performances of rubbery polymers are significantly enhanced when zeolites are incorporated which are carbon dioxide sorption selective, provided that the gas molecules can diffuse through the particles. This is the case when zeolites like silicalite-1, KY and $13 \mathrm{X}$ are considered, leading to separation properties comparable to commonly used glassy polymer membrane materials. The effect is observed even when non-selective or poorly permeable polymers are considered. However, zeolite 5A which seems suitable because of its pore size and hydrophilic character does not show the same positive enhancement.

Furthermore, silicalite-1 was found to be beneficial to the oxygen/nitrogen separation properties of silicone rubber (PDMS) and ethylene-propylene rubber (EPDM) despite its non-selective equilibrium sorption properties.

Finally, carbon molecular sieves do not lead to any significant improvement of the gas separation properties of rubbery polymers (Appendix) due to a dead-end porous structure.

\section{Acknowledgment}

This work was financially supported by Elf Aquitaine (France). 


\section{References}

1 H J C te Hennepe, D Bargeman, M H V Mulder and C A Smolders, Zeolite-filled silicone rubber membranes Part 1 Membrane preparation and pervaporation results, J Membrane Sc1, 35 (1987) 39

2 M Goldman, D Frankel and G Levin, A zeolite/polymer membrane for the separation of ethanol-water azeotrope, J Appl Polym Sc1, 37 (1989) 1791

3 M Jia, K -V Peinemann and R -D Behling, Molecular sieving effect of the zeolite-filled silicone rubber membrane in gas permeation, J Membrane Sc1, 57 (1991) 289.

4 D M Ruthven, Zeolites as selective adsorbents, Chem Eng Prog , 84 (1988) 42

5 D E W Vaughan, The synthesis and manufacture of zeolites, Chem Eng Prog, 84 (1988) 25

6 M E Davis, Zeolites and molecular sieves Not just ordinary catalysts, Ind Eng Chem Res, 30 (1991) 1675

7 R V Jasra, N V Choudary and S G T Bhat, Separation of gases by pressure swing adsorption, Sep Sc1 Technol , 26(7) (1991) 885

8 H J Schroter and H Juntgen, Gas separation by pressure swing adsorption using carbon molecular sieves, in A E Rodrigues, M D Le Van and D Tondeur (Eds), Adsorption Science and Technology, NATO ASI Series E, Applied Science, Vol. 158, Kluwer Academic Publishers, Dordrecht, 1989, p 269

9 H Oda and C Yokokawa, Adsorption of aromatic amines and $\mathrm{O}$-subsituted derivatives of phenol from organic solutions by activated carbons Effect of surface acidity, Carbon, 21 (1983) 485

10 E Plarczyk, H -D Henning and K Knoblauch, Natural gas from landfill gas, Resources and Conservation, 14 (1987) 283

11 I Blume, E Smit, M Wessling and C A Smolders, Diffusion through rubbery and glassy polymer membranes, Makromol Chem, Makromol Symp, 45 (1991) 237

$12 \mathrm{M}$ Wessling, S Schoeman, Th van der Boomgaard and C A Smolders, Plasticization of gas separation membranes, Gas Sep Punf , 5 (1991) 222

13 W J Koros and D R Paul, Design considerations for measurement of gas sorption in polymers by pressure decay, J, Polym Sci, Polym Phys Ed, 14 (1976) 1903

14 L V C Rees, Adsorbent materials Their structure, properties and characterisation, Separation of gases, Proc Fifth BOC Priestley Conference, Birmingham, The Royal Society of Chemistry, 1989, p 245

15 J -M Duval, Adsorbent filled polymeric membranes Application to pervaporation and gas separation, $\mathrm{Ph} D$ Thesis, University of Twente, Enschede, The Netherlands, 1993
16 G M.W Shultz-Sibbel, D T Gjerde, C D Chriswell, J S Fritz and W E Coleman, Analytical investigation of the properties and uses of a new hydrophobic molecular sieve, Talanta, 29 (1982) 447

17 A Seemann, E Richter and H Juntgen, Modelling of a pressure swing adsorption process for oxygen ennchment with carbon molecular sieve, Chem Eng Technol , 11 (1988) 341

18 N Haq and D M Ruthven, Chromatographic study of sorption and diffusion in $4 \mathrm{~A}$ zeohte, $J$ Colloid Interfare Sc1 , 112 (1986) 154

19 D R. Paul and D R Kemp, The diffusion tıme lag in polymer membranes containing adsorptıve fillers, J Polyg Sc1, Part C, 41 (1973) 79

20 S V Moore and D.L Trimm, The preparation of carbon molecular sieves by pore blocking, Carbon, 15 (1977) 177

21 K Chihara and M Suzukı, Control of micropore diffusivities of molecular sieving carbon by deposition of hydrocarbons, Carbon, 17 (1979) 339

$21 \mathrm{JE}$ Koresh and A Soffer, The carbon molecular sieve membranes General properties and the permeability of $\mathrm{CH}_{4} / \mathrm{H}_{2}$ mixture, Sep Sc1. Technol, 22(2/3) (1987) 973

$23 \mathrm{~J}$ E Koresh and A. Soffer, Mechanism of permeation through molecular-sieve carbon membrane Part 1 The effect of adsorption and the dependence on pressure, J Chem Soc , Faraday I, 82 (1986) 2057

\section{Appendix}

Investıgation of carbon molecular sieves as filling material

As indicated above, carbon molecular sieves were also investigated with respect to their effect on the gas separation properties of rubbery polymers. Table A-1 gives some properties of the carbon molecular sieves used. It can be seed that a significant part of the porous volume consists of micropores (diameter $<20 \AA$ ).

Table A-2 gives some gas permeation results obtained with filled membranes using carbon 
TABLE A-1

Main characteristics of the carbon molecular sieves (data from manufacturers)

\begin{tabular}{llll}
\hline & Mean micropore size $(\AA)$ & Micropore vol $\left(\mathrm{cm}^{3} / \mathrm{g}\right)$ & Total pore vol $\left(\mathrm{cm}^{3} / \mathrm{g}\right)$ \\
\hline Cecalite & $6-7$ & 018 & 052 \\
W20 & - & 022 & 055 \\
Carbosieve & $5-7$ & - & - \\
\hline
\end{tabular}

TABLE A-2

Gas separation properties of membranes filled with carbon molecular sieves

\begin{tabular}{lllcl}
\hline & $P_{\mathrm{CO}_{2}}$ (barrer) & $\alpha_{\mathrm{CO}_{2} / \mathrm{CH}_{4}}$ & $P_{\mathrm{O}_{2}}$ (barrer) & $\alpha_{\mathrm{O}_{2} / \mathrm{N}_{2}}$ \\
\hline PDMS & 2920 & 27 & 606 & 21 \\
PDMS+40 wt \% W20 & 3170 & 335 & - & - \\
EPDM & & 43 & 16 & 3 \\
EPDM+30 wt \% W20 & 93 & 48 & - & - \\
EPDM +45 wt \% Cecalite & 55 & 52 & 13 & 43 \\
EPDM +50 wt \% Carbosieve & 120 & 8 & 23 & 43 \\
\hline
\end{tabular}

molecular sieves. It can be seen that in the case of $\mathrm{CO}_{2} / \mathrm{CH}_{4}$ separation no improvement is observed with respect to the properties of PDMS and EPDM, except for Carbosieve. This lack of transport improvement is mainly due to a deadend porous structure, i.e. pores going from the outside to the inside of the particles without being interconnected. Therefore the gas molecules cannot diffuse through the carbon particles, or to a very small extent. To understand better the origin of such a porous structure, one must think of the way carbon molecular sieves are manufactured [7,8]. Though the manufacturing processes are carefully kept secret, it is conjectured that the preparation is based on hard-coal gasification in air followed by a treatment to control the pore structure. This is achieved either by cracking hydrocarbons within the micropore system, resulting in a partial blocking of the pore mouths $[21,22]$, or by mild steam activation which results in an enlargement of the pores.

Both ways result in a macroporous structure from which micropores are developed without interconnection. The selective pores are thus mostly dead-end pores which are effective for use in a pressure swing adsorption process, but not when included into a membrane matrix for a continuous application. Therefore, the applicability of carbon molecular sieves as filling material in a polymer matrix for separation purposes requires an open structure which seems strongly dependent on the method of preparation.

It can be concluded that carbon molecular sieves cannot compete with zeolites as filling material in polymeric membranes for gas separation. The use of a genumely molecular sieve carbon membrane seems more promising, as described in Refs. [22,23]. 